\title{
Evolution de la flore microbienne à la surface des Camemberts fabriqués avec du lait cru
}

\author{
par \\ J. RICHARD \\ Avec la collaboration de J.J. GRATADOUX
}

\section{Ré s u mé}

A cinq reprises au cours d'une année, des Camemberts fabriqués avec du lait cru ont été prélevés dans cinq usines. Ils ont été soumis à une analyse microbiologique de leur flore superficielle aux stades suivants de leur affinage : au démoulage, au sixième jour et une fois par semaine jusqu'à la sixième comprise. Cette analyse comprenait le dénombrement des levures, des bactéries lactiques, des bactéries halotolérantes dont les bactéries corynéformes orange et des bactéries coliformes.

Environ 600 colonies orange ont été prélevées et caractérisées à l'aide de 10 critères physiologiques et biochimiques. Une collection de bactéries coliformes représentative des divers stades d'affinage des fromages a été soumise à 12 tests de façon à faire une identification présomptive des souches la composant. On a également suivi le développement de la flore microbienne à la surface des fromages à l'aide de la microscopie électronique à balayage.

On a constaté des différences significatives entre usines, sur le plan de la nature et/ou du niveau de la flore microbienne se développant à la surface des fromages. Ces différences portaient surtout sur la précocité du développement de la flore halotolérante - des bactéries corynéformes orange en particulier - et le niveau atteint par cette flore en cours d'affinage. Les variations d'une saison à l'autre, pour une même usine, dans la composition ou le niveau de la flore, étaient comparativement faibles.

Les colonies orange étaient en général formées par des bactéries corynéformes capables d'utiliser des acides aminés comme seules sources d'énergie. En particulier, elles étaient presque toutes capables de produire du méthanethiol à partir de la méthionine. Dans une usine, il s'agissait de cocci identifiés au groupe Staphylococcus saprophyticus.

Laboratoire de Microbiologie Laitière, I.N.R.A./C.N.R.Z. - 78350 Jouy-en-Josas. 
Les bactéries coliformes suivaient une évolution comparable à celle trouvée dans les fromages pasteurisés : maximum au démoulage, minimum à environ une semaine puis reprise de la croissance jusqu'en fin d'affinage. Au démoulage, E. coli et Hafnia alvei (souches lactose plus) étaient les deux espèces dominantes. Par la suite, $H$. alvei (lactose plus ou moins) était seul dominant.

La microscopie électronique à balayage a permis de préciser la structure de l'association microbienne à la surface du Camembert et a montré l'état physiologique de quelques micro-organismes. Les conditions de croissance des bactéries à la surface de ce fromage et une possible interaction entre les principaux groupes sont discutés.

Mots clés

Fromage de lait cru - Flore superficielle - Bactéries corynéformes - Bactéries coliformes.

\section{S u m m a ry}

EVOLUTION OF THE MICROBIAL FLORA

OF THE SURFACE OF CAMEMBERT CHEESE MADE FROM RAW MILK

The microbial flora of the surface of Camembert made from raw milk in five factories has been studied 5 times over one year. As a rule, the manufacturing milk was prepared with at least 50 per cent of milk not cooled at the farn. In addition, an attempt of making cheese with 100 per cent refrigerated milk was carried out in one factory.

Salt tolerant bacteria (Mannitol Salt Agar), coliform bacteria, yeasts and lactic acid bacteria were enumerated at taking out from moulds and at approximatively one week intervals up to the end of the ripening period (6th weeks). About 600 orange opaque colonies were isolated from Mannitol Salt Agar and characterized using 10 tests : cell morphology after one day of growth in Brain Heart Infusion Broth, colony colour change in presence of $5 \mathrm{~N} \mathrm{NaOH}$, utilization of 4 amino acids (Ser, Met, Phe, Orn) and resistance to 4 antibiotics. A collection of coliform bacteria representative of all stages of ripening were submitted to 12 tests (growth at 7, 41 and $45^{\circ} \mathrm{C}$; acid production from lactose, sorbitol, adonitol, salicine, rhamnose and inositol; indol production; hydrolysis of tributyrin and casein) for presumptive identification. In addition, the evolution of the microbial flora was followed by scanning electron microscopy.

The largest differences between factories were observed in nature and/or level of salt tolerant bacteria. In one factory, the growth of this flora started earlier and attained a higher level on cheese than on those made in the other factories. Comparatively, smaller difference in nature or level of the flora was observed between seasons. The lower level of lactic acid bacteria were observed when 100 per cent refrigerated milk was used. 
Usually, the orange pigmented colonies were coryneform bacteria able to utilize the amino acids and particularly methionin (to produce methanethiol, a precursor of sulfur compounds which play an important role in the flavour of this type of cheese). In one factory, orange pigmented cocci (Staphylococcus saprophyticus group) were sometimes dominant. These bacteria were generally unable to utilize amino acids.

Coliform bacteria attained the highest level on cheese surface at taking out from moulds (E. coli, and lactose-positive strains of Hafnia alvei dominating) and at the end of the ripening period (lactose-positive and lactose-negative strains of $\mathrm{H}$. alvei dominating) with a minimum after 1 week.

Scanning electron microscopy revealed the nature of the association between micro-organisms and theyr physiological state.

Conditions of growth of bacteria and possible interaction between the micro-organisms found on the surface of Camembert are discussed.

Key words

Camembert made of raw milk - Microbial flora - Coryneform bacteria Coliform bacteria.

\section{INTRODUCTION}

Dans une précédente étude (Richard et Zadi, 1983) nous avons montré que la flore bactérienne se développant, en cours d'affinage, à la surface de Camemberts fabriqués avec du lait cru était complexe et que de grandes différences dans sa nature apparaissaient entre usines et, semble-t-il aussi, d'une saison à l'autre.

Nous avons voulu confirmer ces observations, en nous intéressant aux bactéries coliformes, en raison de leur intérêt hygiénique (et peutêtre technologique), et aux bactéries halotolérantes et en particulier aux bactéries donnant des colonies orange ( ferment du rouge »), dont on pense qu'elles jouent un rôle important dans l'affinage de ces fromages (Sansonnetti, 1930).

\section{MATERIEL ET METHODES}

\section{Origine et traitement des échantillons}

A cinq reprises au cours d'une année (août, octobre, janvier, mars et juin) des fromages ont été prélevés à différents stades de leur affinage (au démoulage, au sixième jour puis chaque semaine jusqu'à la sixième comprise) dans quatre des cinq usines ayant fait l'objet de notre étude préliminaire (usines I à IV). Chaque usine utilisait du lait cru mais présentait des variantes dans la fabrication (tableau 1). En particulier, seule 


\section{TABLEAU 1 - TABLE 1}

Quelques caractéristiques des fabrications suivies au cours de l'étude

Some characteristics of the cheese manufacture

\begin{tabular}{l|c|c|c|c|c}
\hline Usine & $\begin{array}{c}\text { Pourcentage } \\
\text { de lait } \\
\text { réfrigéré }\end{array}$ & $\begin{array}{c}\text { Maturation } \\
\text { avec } \\
\text { levain }\end{array}$ & $\begin{array}{c}\text { Moulage } \\
\text { du } \\
\text { caillé }\end{array}$ & $\begin{array}{c}\text { Mode } \\
\text { de } \\
\text { salage }\end{array}$ & $\begin{array}{c}\text { \&lanchage } \\
\text { des } \\
\text { fromages }\end{array}$ \\
\cline { 2 - 3 } I & $50-80$ & + & mécanique & saumure & - \\
II & 0 & + & à la louche & sel sec & - \\
III & 0 & + & à la louche & sel sec & + \\
IV & 0 & + & à la louche & sel sec & + \\
IV R & 100 & + & à la louche & sel sec & + \\
V & 0 & + & à la louche & sel sec & - \\
VI & 50 & - & à la louche & sel sec & - \\
\hline
\end{tabular}

l'usine I pratiquait un moulage mécanisé du caillé ; dans l'usine IV, on effectuait, à titre expérimental, des fabrications (notées IVR) exclusivement avec du lait réfrigéré. Les fromages ont été affinés à l'usine en haloir à $10-12^{\circ} \mathrm{C}$ jusqu'à la deuxième semaine environ puis ils ont été emballés et conservés en chambre froide au C.N.R.Z. à une température comprise entre 4 et $6^{\circ} \mathrm{C}$. Ceux des usines V (la même que dans l'étude préliminaire) et VI ont été examinés à deux reprises seulement (août et octobre pour l'usine V, et mars et juin pour l'usine VI).

Les échantillons de croûte de fromage ont été prélevés et traités comme indiqué dans notre précédent article sauf que la solution de citrate a été remplacée par une solution de bouillon cour-cervelle BHI (Brain Heart Infusion, Difco) à $37 \mathrm{~g} / 1$ contenant $5 \mathrm{~g} / 1$ de Tween 80 pour émulsifier la matière grasse. On obtenait ainsi une suspension plus homogène. Celle-ci était conservée à $0^{\circ} \mathrm{C}$ une heure au plus avant l'analyse microbiologique.

\section{Dénombrement des bactéries lactiques et des levures}

Ces deux groupes microbiens ont été évalués sur les milieux suivants :

- Bactéries lactiques : milieu BHI additionné de $50 \mathrm{mg} / 1$ de Fungizone (Squibb) et de $40 \mathrm{mg} / \mathrm{l}$ d'acide nalidixique (Sigma) pour inhiber respectivement les levures et les bactéries Gram-négatif. Une étude 
complémentaire a montré que les colonies plates, translucides, non pigmentées, d'un diamètre inférieur à $3 \mathrm{~mm}$ étaient très généralement des streptocoques lactiques.

- Levures : milieu YEDC (Yeast Extract Dextrose Chloramphenicol (anon., 1980) ou milieu BHI addtionné d'acide nalidixique (40 mg/1) et de pénicilline G (100 Ul/ml) qui s'est révélé équivalent (Gratadoux et Richard, résultats non publiés).

Après ensemencement en surface à l'aide d'un appareil Spiral Plater (Interscience, France), les boîtes ont été incubées 3 jours à $30^{\circ} \mathrm{C}$.

\section{Dénombrements de la flore halotolérante et caractérisation des colonies orange}

Les bactéries halotolérantes ont été dénombrées sur milieu salé au mannitol (Mannitol Salt Agar, Difco) additionné de $50 \mathrm{mg} / 1$ de Fungizone (Squibb) pour inhiber les levures et de $5 \mathrm{~g} / 1$ de carbonate de calcium pour éviter une acidification éventuelle du milieu (Richard et Zadi, 1983).

Ce milieu a été ensemencé en surface, à l'aide du Spiral Plater, et les différents types de colonies obtenus (opaques et pigmentées, jaunes, oranges ou blanches ou translucides, pigmentées ou non) ont été dénombrées comme indiqué précédemment (Richard et Zadi, 1983), après 3 jours d'incubation des boîtes de Petri à $30^{\circ} \mathrm{C}$ puis 15 jours environ à température ambiante.

Dès que le niveau des colonies orange atteignait $10^{6} / \mathrm{g}$ (en général à la troisième ou quatrième semaine d'affinage) et en fin d'affinage, on prélevait 16 colonies par boîte de Petri et on les purifiait à deux reprises selon une méthode rapide (Richard, 1981ª).

D’une étude préliminaire (Zadi, 1981), nous avons sélectionné dix critères permettant, d'une part, de séparer les bactéries corynéformes des staphylocoques et, d'autre part, de révéler des différences éventuelles à l'intérieur de chacun de ces groupes. Les tests sont les suivants :

a) Morphologie des cellules à l'état frais après $24 \mathrm{~h}$ à $30^{\circ} \mathrm{C}$ de culture sur bouillon $\mathrm{BHI}$;

b) Production d'une teinte rouge des colonies orange au contact d'une solution de soude $5 \mathrm{~N}$ (Jones et al., 1973);

c) Utilisation, comme seules sources de carbone, des quatre acides aminés suivants : L-méthionine, L-phénylalanine, L-ornithine, L-sérine. Des solutions concentrées de ces composés ont été stérilisées par filtration (porosité $0,45 \mu \mathrm{m}$ ) et additionnées (concentration finale $0,4 \%$ ) à un milieu minéral de base (Richard, $1981^{\mathrm{b}}$ ) complété par un mélange de vitamines (Bousfield, 1972). Après 3-4 jours d'incubation à $28^{\circ} \mathrm{C}$, les boîtes inoculées étaient laissées 17 à 18 jours à température ambiante. Un témoin sans substrat permettait, par comparaison, de repérer la croissance des bactéries; 
d) Croissance en présence de carbénicilline (1 $\mu \mathrm{g} / \mathrm{ml})$, gentamycine $(0,2 \mu \mathrm{g} / \mathrm{ml})$, rifamycine $(0,1 \mu \mathrm{g} / \mathrm{ml})$ et bacitracine $(0,1 \mathrm{UI} / \mathrm{ml})$ en 7 jours à $30^{\circ} \mathrm{C}$ sur milieu Mueller-Hinton (Institut Pasteur Production).

\section{Dénombrement des bactéries coliformes et identifications des espèces dominantes}

Les bactéries coliformes ont été dénombrées sur milieu lactosé bilié contenant du cristal violet et du rouge de méthyle (VRB, Difco 12). Le milieu a été ensemencé en surface à l'aide de l'appareil Spiral Plater. Contrairement à ce qui a été recommandé (anon., 1974), on ne l'a pas recouvert d'une mince couche de gélose, de façon à ne pas modifier la répartition de l'inoculum.

Après 24 heures d'incubation à $30^{\circ} \mathrm{C}$, on a dénombré séparément les colonies lactose plus (lactose + ) et les colonies lactose moins (lactose -).

Pour vérifier s'il s'agissait effectivement de bactéries coliformes, on a prélevé, sur des boîtes correspondant à différents stades d'affinage, 8 colonies de chaque type. Après purification suivant une méthode rapide (Richard, $1981^{\text {a }}$ ) on a déterminé la voie de métabolisme du glucose de ces bactéries par la technique à un tube (Park et Holding, 1966). Ces bactéries ont été ensuite caractérisées à l'aide des critères suivants :

a) Culture sur milieu VRB après $24 \mathrm{~h}$ à 41 et $45^{\circ} \mathrm{C}$ et après 10 jours à $7^{\circ} \mathrm{C}$;

b) Production d'acide en $24 \mathrm{~h}$ à $30^{\circ} \mathrm{C}$ à partir du lactose, du sorbitol, de la salicine, du rhamnose, de l'inositol et de l'adonitol. Des solutions concentrées de ces sucres et dérivés ont été stérilisées par filtration (porosité $0,45 \mu \mathrm{m}$ ) et ajoutées à raison de $10 \mathrm{~g} / \mathrm{l}$ à du bouillon Purple Broth Base (Difco) ;

c) Production d'indole, sur milieu SIM (Sulfide Indole Motility, Difco 271), après 20 à $24 \mathrm{~h}$ à $30^{\circ} \mathrm{C}$. La lecture est faite par addition d'une goutte de réactif de kovacs sur la colonie : l'apparition d'une coloration rouge indique une réaction positive.

Nous avons introduit le test $a$ pour tenter de séparer les coliformes de l'environnement des coliformes fécaux (Gavini et al., 1980). Les tests $b$ et $c$ ont été sélectionnés après l'étude préliminaire (Richard et Zadi, 1983) pour distinguer les principales espèces de coliformes trouvées dans ce fromage (identification présomptive, sur la base d'un faible nombre de critères miniaturisés et peu coûteux, des espèces Escherichia coli et Hafnia alvei).

Enfin, deux autres tests, d'intérêt taxonomique et technologique, ont été effectués : de caséine ;

- hydrolyse de la caséine, sur Nutrient Agar additionné de $2 \%$

- hydrolyse de la tributyrine, sur Nutrient Agar additionné de $1 \%$ de tributyrine émulsionnée dans un volume égal d'eau distillée 


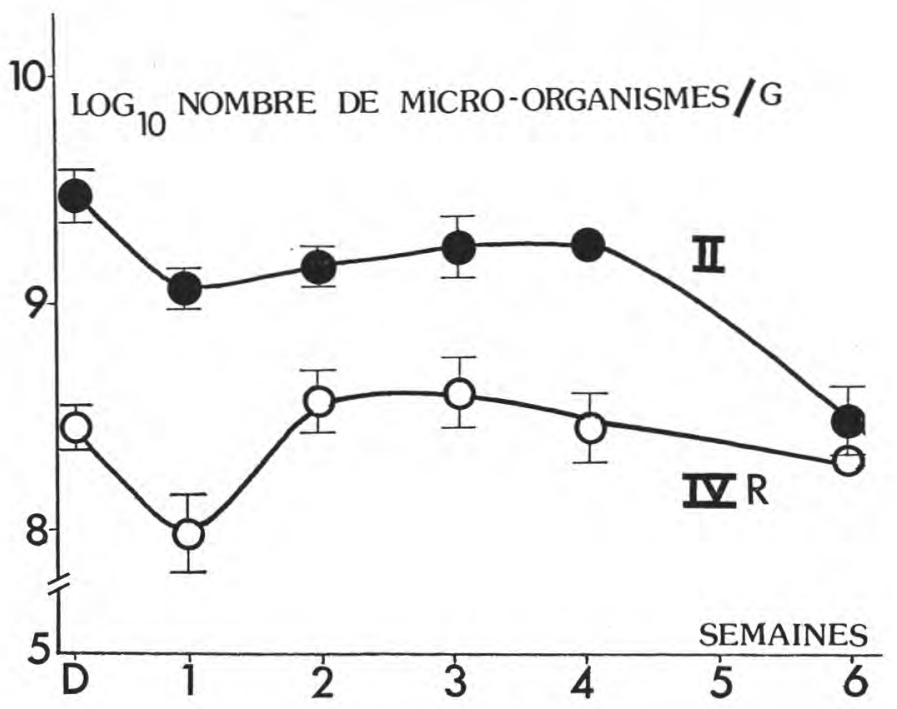

fig. 1

Evolution de la flore lactique à la surface des fromages de deux usines (moyenne logarithmique des résultats obtenus à diverses périodes de l'année, avec intervalle de confiance à $\mathrm{P}=95 \%$ ).

IV R : Usine ayant le niveau le plus faible (fabrication avec du lait réfrigéré) et II : Usine ayant le niveau le plus élevé (fabrication avec du lait non refroidi). D : Fromage au démoulage.

Evolution of the lactic flora growing on the surface of cheese made from raw milk in manufactures having the highest and the lowest level of these bacteria (geometric meam and interval of confidence of counts obtained at several periods of one year).

$I V R$ and II : Cheese made with refrigerated and not cooled milk respectively. $D$ : Cheese at taking out from moulds.

contenant $2 \%$ d'un détergent non ionique (Triton X100) comme agent disperseur.

Ces deux réactions d'hydrolyse se traduisent après incubation à $30^{\circ} \mathrm{C}$ pendant $24 \mathrm{~h}$, par une auréole translucide autour de la colonie.

Une collection de 150 souches, qualitativement représentatives des principaux types de bactéries trouvés, a été soumise à une identification à l'aide des galeries API $20 \mathrm{E}$ et à une étude de confirmation, sur 74 souches, par une galerie mise au point pour la flore coliforme des eaux (Gavini et al., 1982).

Pour tous les tests de différenciation indiqués dans les deux paragraphes précédents, nous avons utilisé la technique de réplique sur boîtes à 25 cases ou 96 cupules, avec l'appareil « Multipoint Inoculator » (Denley, England). 


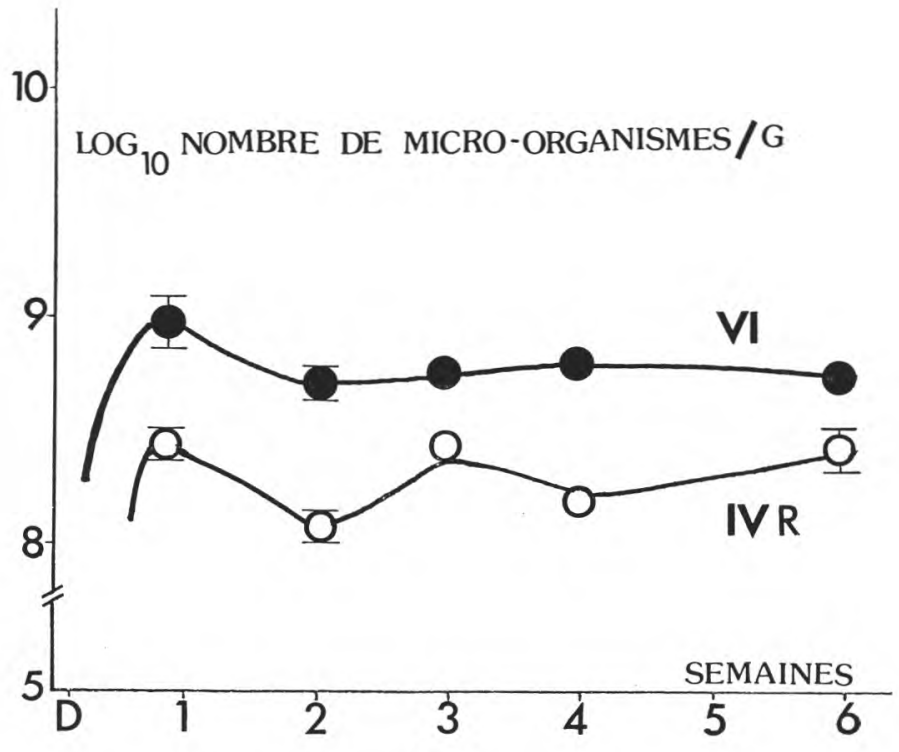

fig. 2

Evolution de la flore levure à la surface des fromages (légende, voir fig. 1). Evolution of yeast at the surface of cheese (key as to Fig. 1).

\section{Examen de la surface des fromages au microscope électronique à balayage}

Le développement du Penicillium, du Goetrichum et des levures ainsi que des bactéries a été suivi à l'aide de la microscopie à balayage (Rousseau, 1984), à deux reprises sur des fromages de deux fabrications (usines III et IV) âgés de 2 à 9 jours puis après 2, 3, 4, 5 et 6 semaines d'affinage.

\section{RESULTATS}

\section{Dénombrements microbiens}

Pour la plupart des groupes microbiens dénombrés, les variations des résultats d'une usine à l'autre étaient nettement plus importantes que d'une époque à l'autre pour une même usine. Nous avons donc établi une courbe moyenne annuelle pour chaque usine, ainsi que l'intervalle de confiance à $95 \%$ de chaque point constitutif.

\section{a) Bactéries lactiques}

La figure 1 montre le niveau le plus faible et le niveau le plus élevé atteint par les six usines pour ce groupe microbien. 


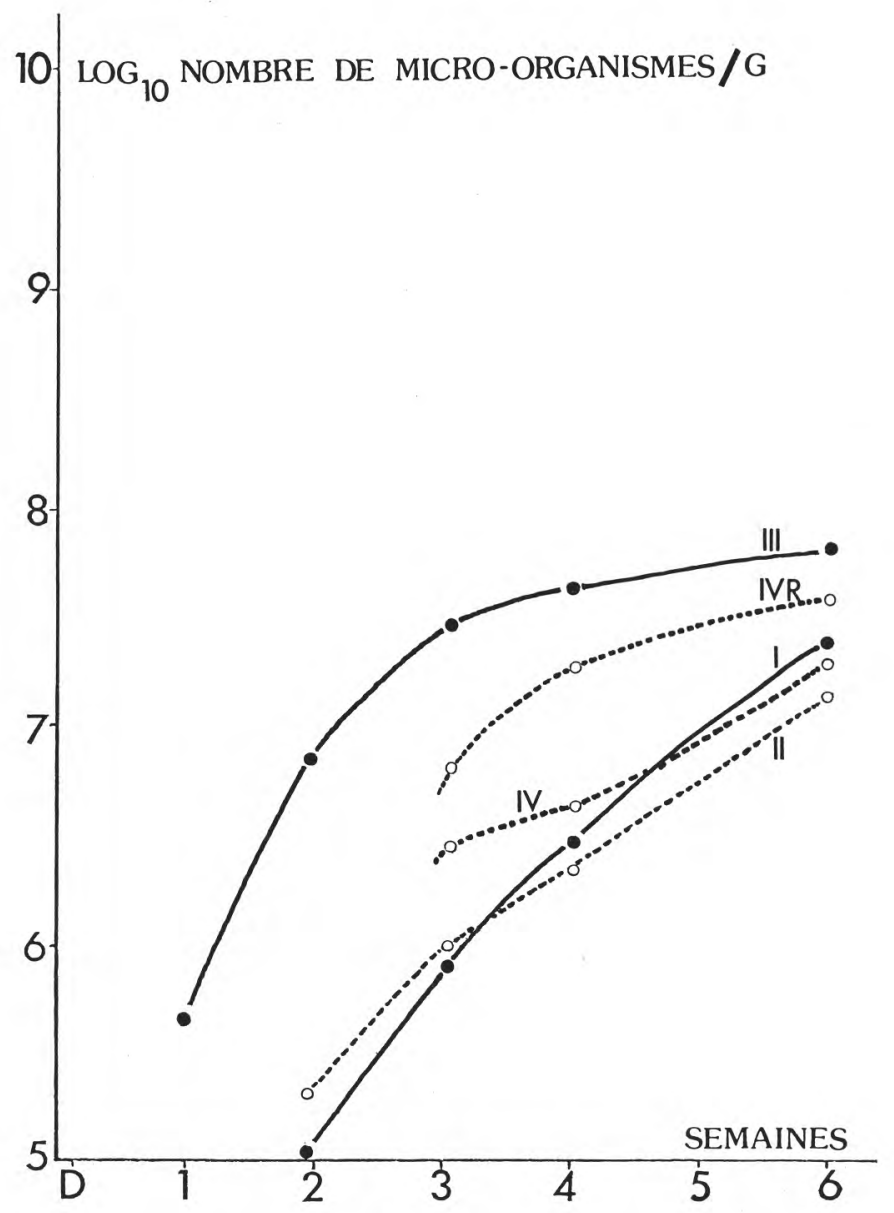

fig. $3(a)$

fig. 3

Evolution de la flore halotolérante à la surface des fromages. Bactéries donnant des colonies blanches opaques (a), jaunes opaques (b), translucides (c).

Evolution of the halotolerant flora on the surface of cheese. Bacteria giving white opaque colonies $(a)$, yellow opaque colonies $(b)$, translucent colonies $(c)$. (Enumeration at the surface of the Mannitol Salt Agar medium after an incubation of $3 d$ at $30^{\circ} C$ and 2 weeks at $R T$ ).

Les autres courbes présentaient aussi un minimum après une semaine puis, en général, une remontée plus ou moins nette suivant les usines. Celles des usines III, IV et V se confondaient pratiquement avec 


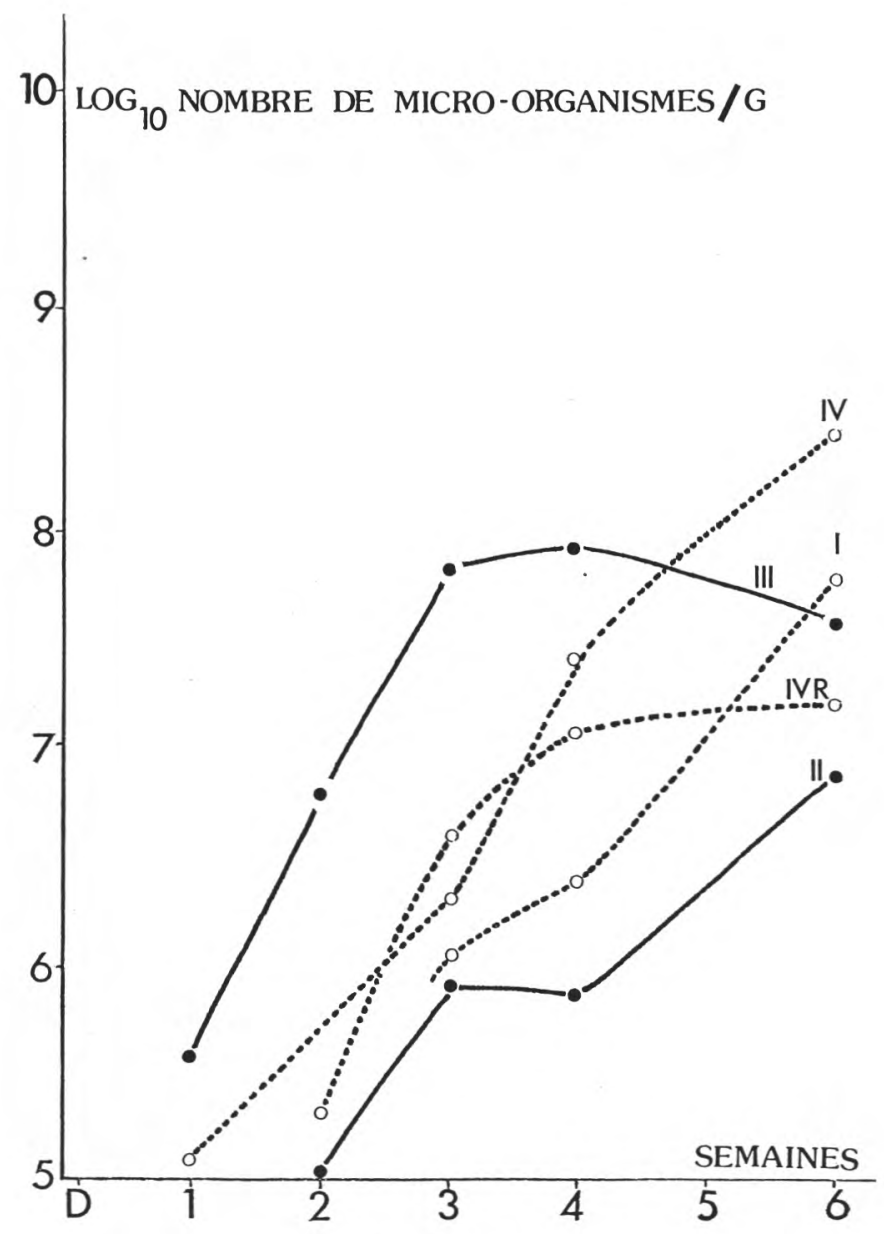

fig. $3(b)$

celle de l'usine II (lait non réfrigéré dominant dans ces quatre usines). Par contre, celle de l'usine I (lait en partie réfrigéré) était plus proche de celle de l'usine IV R (lait entièrement réfrigéré) que des précédentes et ne présentait pas de remontée. On notera la relativement faible variation annuelle du niveau de la flore lactique à l'intérieur d'une même usine (intervalle de confiance inférieur à un tiers d'unité de logarithme).

\section{b) Levures}

L'évolution de la flore levure à la surface des fromages de deux usines est présentée sur la figure 2 . Les courbes non représentées avaient une forme ondulante semblable à celle de l'usine IV R. Aucune diffé- 


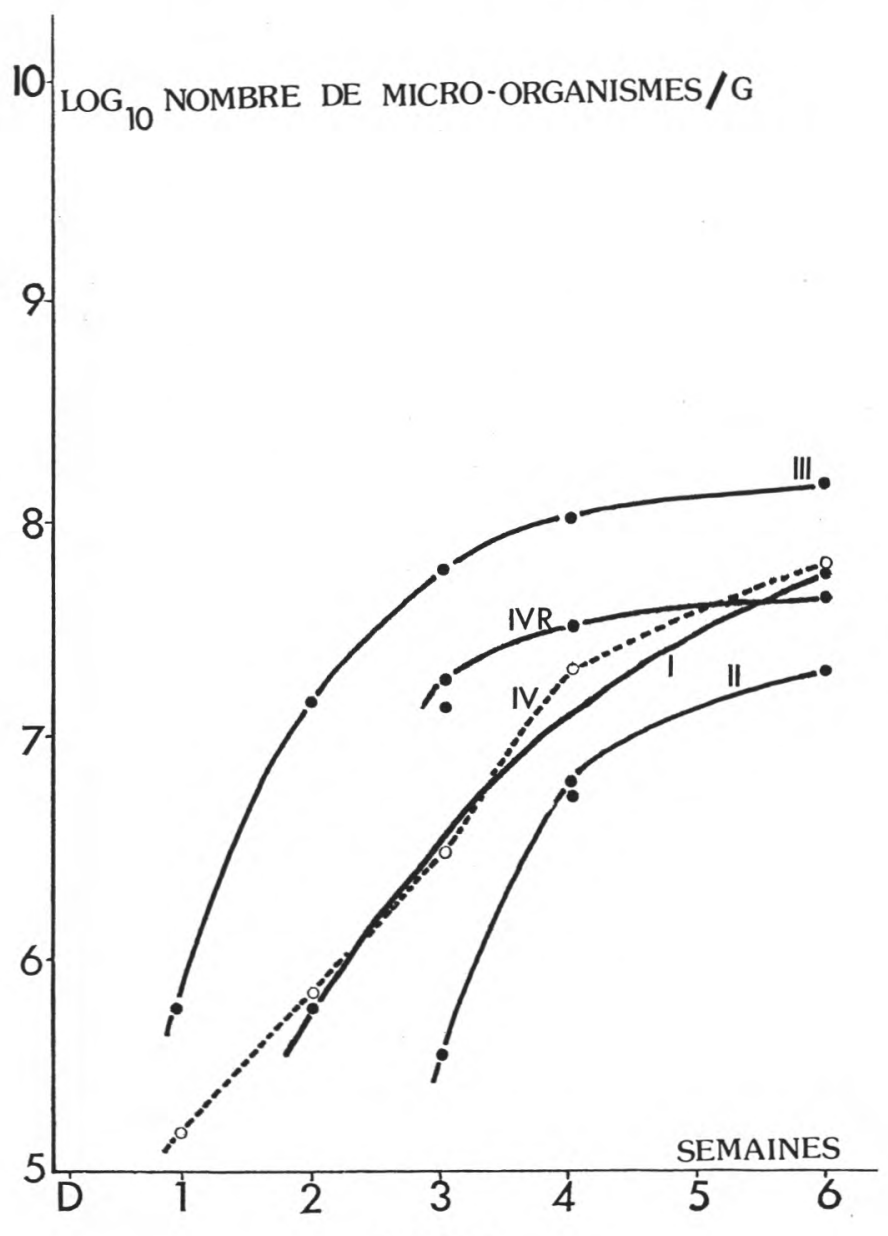

fig. 3 (c)

rence nette entre elles n'était observée. On notera comme précédemment la faible variation annuelle (au plus, un quart d'unité de log).

c) Bactéries halotolérantes

Les courbes moyennes de chaque usine pour les principaux types de colonies trouvées sur le milieu salé sont présentées sur les figures 3 et 4. Pour plus de clarté, on n'a pas représenté l'intervalle de confiance de toutes les courbes. Celui-ci était en général de même ordre de grandeur pour toutes les usines.

On rappelle que dans l'étude préliminaire (Richard et Zadi, 1983) les colonies blanches étaient habituellement des bactéries corynéformes 


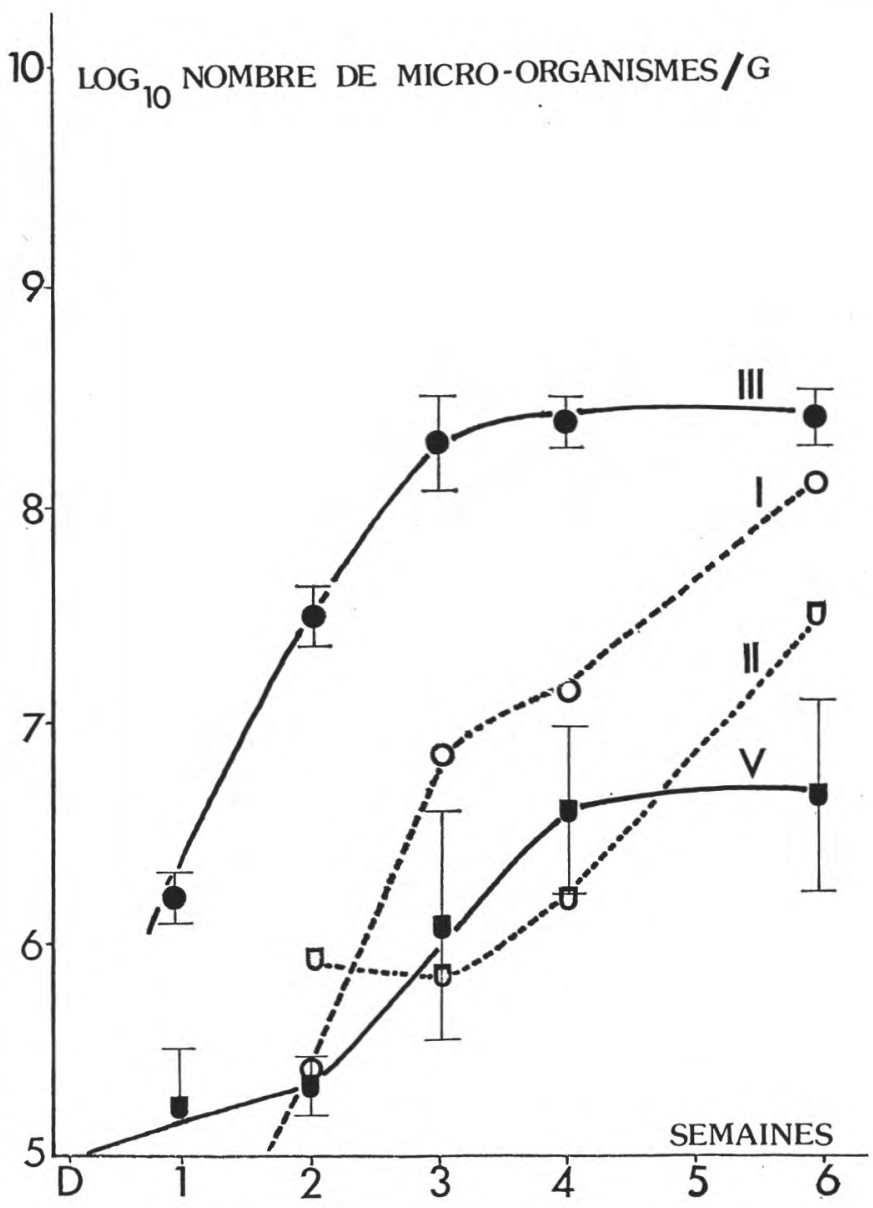

fig. 4

Evolution des bactéries corynéformes orange à la surface des fromages.

Evolution of orange coryneform bacteria on the surface of cheese.

ou des staphylocoques saprophytes, les jaunes des bactéries corynéformes ou du genre Micrococcus et les translucides, peu ou pas pigmentées, des bactéries intermédiaires entre les genres Moraxella et Acinetobacter.

Avec ces trois groupes microbiens (figures $3 a, b$ et $c$ ) on observe, comme dans cette étude préliminaire, de grandes différences d'une usine à l'autre quant au niveau de la flore et à la forme des courbes. On notera, en particulier, le niveau supérieur atteint, pour ces trois groupes, par l'usine III et le niveau inférieur par l'usine II. 
LOG $_{10}$ NOMBRE DE MICRO-ORGANISMES/G
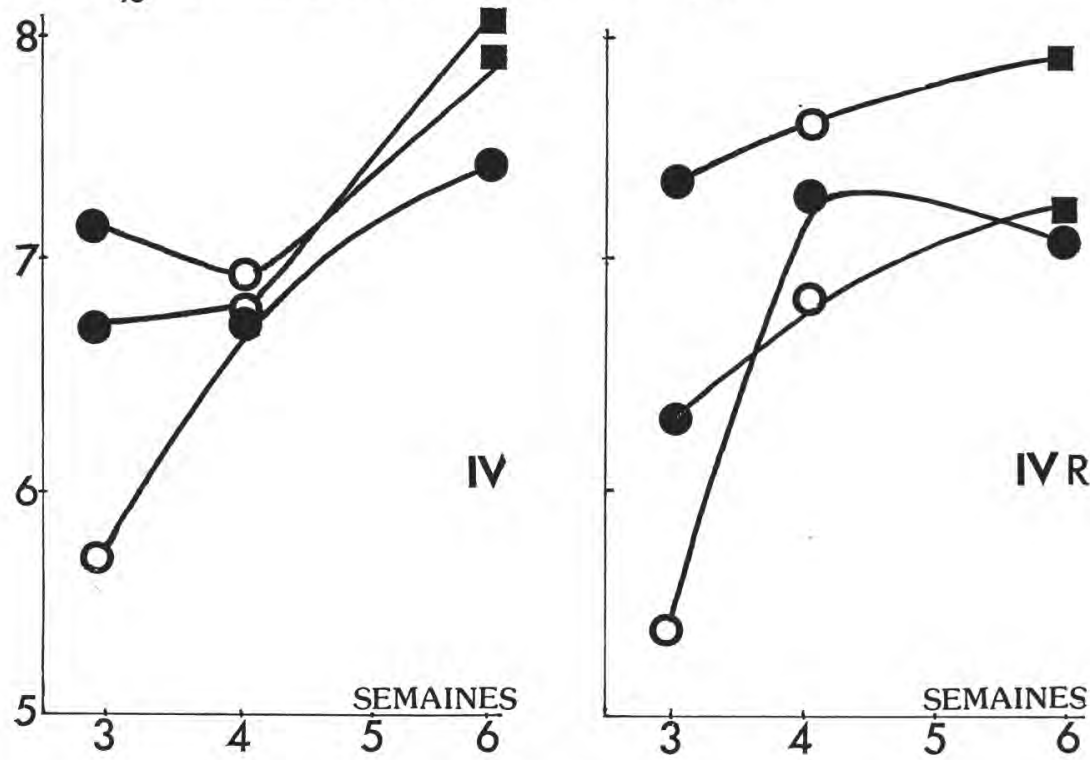

fig. 5

Evolution à la surface des fromages, des bactéries donnant des colonies orange. : staphylocoques du groupe S. saprophyticus ; : bactéries corynéformes.

Evolution of orange bacteria on the surface of cheese. : staphylococci belonging to the $\mathrm{S}$. saprophyticus group; coryneform bacteria.

C'est également la même usine III qui fournissait, de loin, les fromages les plus peuplés en bactéries corynéformes orange (figure 4). Ces bactéries atteignaient un niveau important (plus de $10^{8} / \mathrm{g}$ ) dès la troisième semaine d'affinage alors que, dans les usines I et II par exemple, il était atteint seulement à la sixième. Dans l'usine IV (figure 5), on avait des fromages sur lesquels on a trouvé, dans les deux types de fabrication, à la troisième ou à la quatrième semaine, des cocci Gram positif (sans doute des staphylocoques saprophytes) puis des bactéries corynéformes en fin d'affinage.

Les caractéristiques des principaux types de bactéries corynéformes et de cocci isolés de la surface des fromages sont présentées dans le tableau 2. Les cocci provenaient essentiellement de l'usine IV.

On notera que la plupart des bactéries corynéformes utilisent la méthionine comme seule source de carbone, catabolisme qui s'accompagne "in vitro » de libération de méthanethiol (Hemme et Richard, 1985). Ce composé est un précurseur des produits volatils soufrés qui confèrent à ce type de fromages leur flaveur alliacée (Dumont et al., 
TABLEAU 2 - TABLE 2

Principaux types de bactéries orange isolées des Camemberts durant 1 an Most frequent types of orange pigmented bacteria isolated from cheese surface during one year period

\begin{tabular}{|c|c|c|c|c|c|c|c|c|c|c|c|}
\hline \multirow[b]{2}{*}{ Profil $n^{\circ}$} & \multicolumn{6}{|c|}{ Bactéries corynéformes } & \multicolumn{5}{|c|}{ Cocci } \\
\hline & 1 & 2 & 3 & 4 & 5 & 6 & 7 & 8 & 9 & 10 & 11 \\
\hline $\begin{array}{l}\text { Tests } \mathrm{NaOH} \\
\text { Résistance à : }\end{array}$ & + & + & + & + & + & + & - & - & - & - & - \\
\hline $\begin{array}{l}\text { Bacitracine } \\
\text { Carbénicilline } \\
\text { Gentamycine } \\
\text { Rifamycine }\end{array}$ & $\begin{array}{l}- \\
+ \\
+ \\
+\end{array}$ & $\begin{array}{l}- \\
+ \\
+ \\
-\end{array}$ & $\begin{array}{l}+ \\
+ \\
+ \\
+\end{array}$ & $\begin{array}{l}- \\
+ \\
+ \\
-\end{array}$ & $\begin{array}{l}- \\
+ \\
+ \\
+\end{array}$ & $\begin{array}{l}- \\
+ \\
+ \\
+\end{array}$ & $\frac{+}{+}$ & $\begin{array}{l}+ \\
+ \\
+\end{array}$ & $\begin{array}{l}+ \\
+ \\
+\end{array}$ & $\begin{array}{l}+ \\
+ \\
+\end{array}$ & $\begin{array}{l}+ \\
- \\
-\end{array}$ \\
\hline $\begin{array}{l}\text { Utilisation de : } \\
\text { Méthionine } \\
\text { Phénylalanine } \\
\text { Ornithine } \\
\text { Sérine }\end{array}$ & $\begin{array}{l}+ \\
+ \\
+ \\
+\end{array}$ & $\begin{array}{l}+ \\
+ \\
+ \\
+\end{array}$ & $\begin{array}{l}+ \\
+ \\
+ \\
+\end{array}$ & $\begin{array}{l}+ \\
+ \\
+ \\
-\end{array}$ & $\begin{array}{l}- \\
+ \\
+ \\
+\end{array}$ & $\begin{array}{l}+ \\
+ \\
+ \\
-\end{array}$ & $\begin{array}{l}- \\
- \\
-\end{array}$ & $\begin{array}{l}- \\
- \\
-\end{array}$ & $\begin{array}{l}- \\
\overline{+} \\
+\end{array}$ & $\begin{array}{l}- \\
\overline{+}\end{array}$ & $\begin{array}{l}- \\
- \\
-\end{array}$ \\
\hline $\begin{array}{l}\text { Nombre de souches } \\
\%^{*}\end{array}$ & $\begin{array}{r}156 \\
33\end{array}$ & $\begin{array}{r}101 \\
22\end{array}$ & $\begin{array}{r}35 \\
7.5\end{array}$ & $\begin{array}{r}28 \\
6.0\end{array}$ & $\begin{array}{r}24 \\
5.1\end{array}$ & $\begin{array}{r}20 \\
4.3\end{array}$ & $\begin{array}{l}30 \\
25\end{array}$ & $\begin{array}{l}30 \\
25\end{array}$ & $\begin{array}{l}20 \\
17\end{array}$ & $\begin{array}{c}9 \\
7.6\end{array}$ & $\begin{array}{c}9 \\
7.6\end{array}$ \\
\hline
\end{tabular}

* Pourcentages basés sur 468 bactéries corynéformes et 118 cocci. 


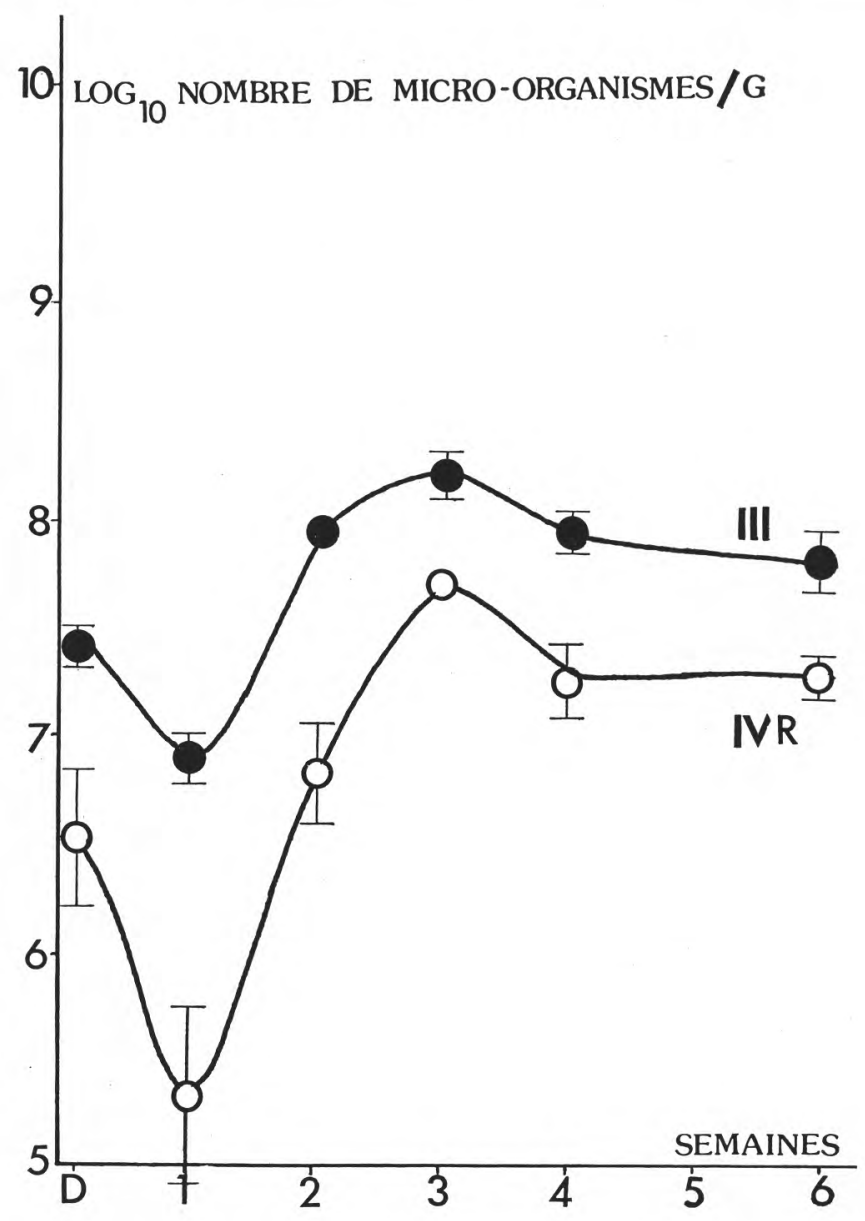

fig. $6($ a)

Evolution de la flore coliforme à la surface des fromage : (a) colonies lactose plus ; (b) colonies lactose moins.

Evolution of coliform bacteria on the surface of cheese : (a) and (b) lactose positive and lactose négative colonies respectively.

1976). Elles utilisent également les autres acides aminés, ce qui montre un pouvoir catabolique supérieur à celui des cocci.

On n'a pas observé, entre usines, de différences significatives dans les types de bactéries corynéformes orange excepté le fait que l'usine I avait la flore la plus homogène et l'usine III la plus hétérogène : dans 


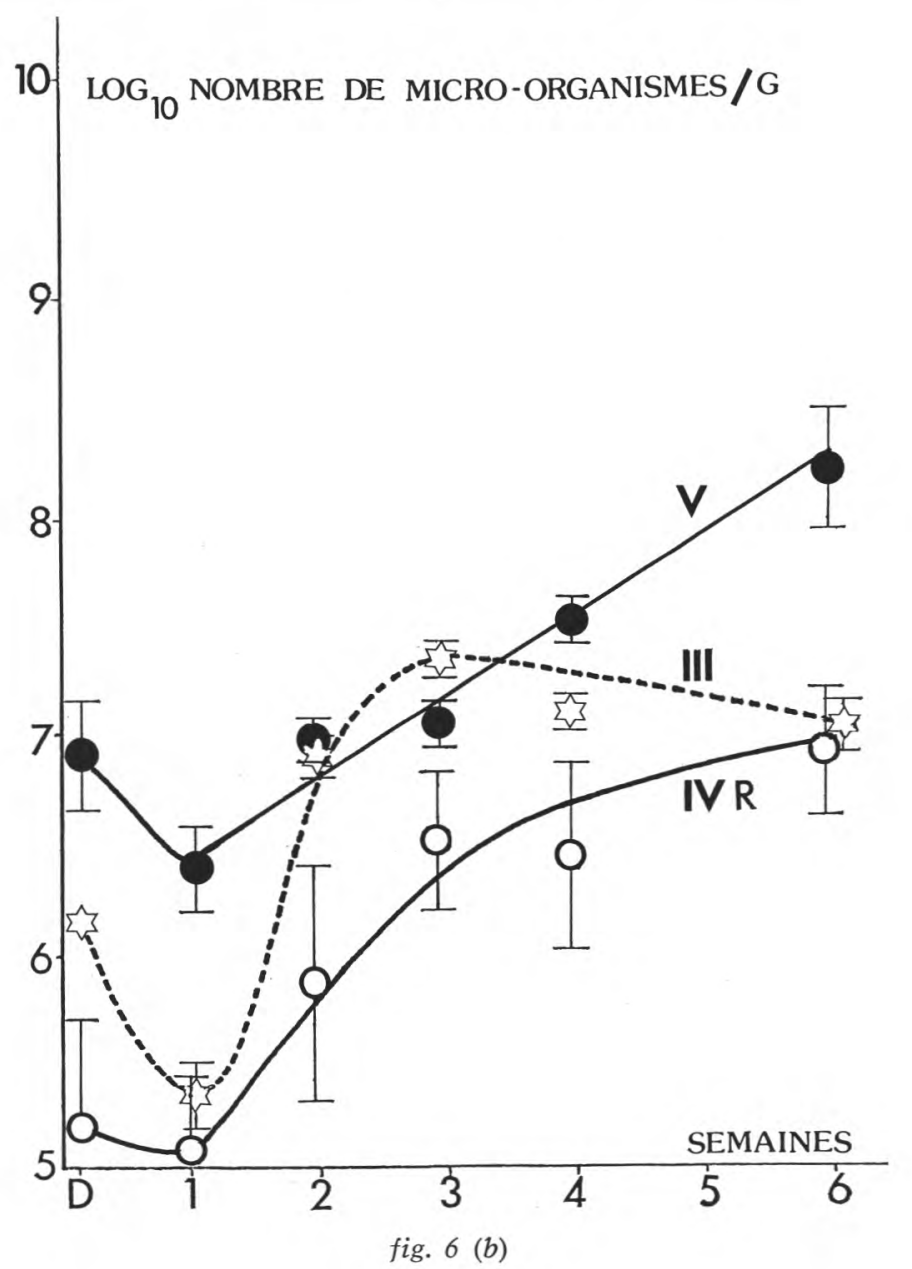

la première, trois types seulement $(1,2$ et 3$)$ représentaient environ $85 \%$ de la flore, alors qu'il en fallait douze dans la seconde, les types 1 à 3 ne représentant que $43 \%$ de cette flore. De même, on n'a pas observé de différence dans le type de bactéries entre le début de leur apparition dans le fromage et la fin de l'affinage, ni d'une saison à l'autre ; cela peut être dû au fait que le nombre de colonies caractérisées par fromage était trop faible, compte tenu du nombre de types différents.

d) Bactéries coliformes

Les résultats des dénombrements des colonies lactose + et lactose - ont permis d'établir les courbes présentées sur la figure 6 ( $a$ et $b$ ). Les courbes de toutes les usines avaient la même allure : d'abord, 
diminution très forte de la population microbienne entre le démoulage des fromages et la première semaine, suivie d'une remontée. Celle-ci était en général plus importante pour les bactéries lactose + que pour les bactéries lactose -

Avec la plupart des fabrications, on observait ensuite un fléchissement de la population de bactéries lactose + , mais pas des bactéries lactose -, sauf pour l'usine III.

On remarquera la position supérieure des courbes de l'usine III et la position inférieure des courbes relatives aux fabrications faites exclusivement avec du lait réfrigéré (usine IV R).

Au total, 616 colonies dont 384 lactose - ont été soumises au test de fermentation du glucose. Toutes les souches lactose + étaient fermentatives; les souches lactose - également, sauf dans les fromages au démoulage ou en fin d'affinage, dans lesquels nous avons trouvé environ $10 \%$ de souches non fermentatives. A cette réserve près, on peut donc considérer que le dénombrement à la surface du milieu VRB, sans le recouvrement habituel d'une fine couche de milieu, permet une estimation correcte du niveau des bactéries coliformes dans ce type de fromages.

Près d'un millier de souches (652 lactose + et 343 lactose - ) ont été caractérisées sur la base des douze critères décrits plus haut.

Les profils les plus fréquemment rencontrés de bactéries lactose + et lactose - sont présentés dans les tableaux 3 et 4 .

Les souches lactose + de la collection qualitativement représentative appartenaient, quelle que soit la méthode d'identification utilisée, à deux espèces, surtout : Hafnia alvei (profils 1 à 4 du tabeau 3 ) et Escherichia coli (profils 5 à 7), cette dernière se distinguant des autres espèces trouvées essentiellement par la production d'indole et la croissance à $45^{\circ} \mathrm{C}$ (mais pas à $7^{\circ} \mathrm{C}$ ). La plupart des souches identifiables à H. alvei étaient par contre psychrotrophes, une partie d'entre elles pouvant cependant pousser à $41^{\circ} \mathrm{C}$ (souches eurithermiques). Les autres espèces rencontrées comprenaient surtout Serratia liquefaciens (bactéries lipolytiques et protéolytiques) et Citrobacter freundii.

La figure 7 montre les proportions de ces quatre espèces dans les fromages, en fonction du stade de leur affinage. On notera la proportion croissante des bactéries identifées à $H$, alvei.

Par ailleurs, les souches lactose - ont été identifiées à $H$. alvei (profils 1 à 3 du tableau 4) et à Serratia liquefaciens (profils 4 et 5). Cette dernière espèce n'a été trouvée qu'au début de l'affinage des fromages (au démoulage et à la première semaine). On notera que toutes sont psychrotrophes.

\section{Examens au microscope électronique à balayage}

Les levures apparaissaient sur les fromages dès le deuxième jour de leur fabrication et formaient une couche d'épaisseur croissante (jusqu'à 
TABLEAU 3 - TABLE 3

Profils les plus fréquents des bactéries coliformes lactose plus à la surface des fromages Most frequent types of lactose-positive coliform bacteria on the surface of cheese

\begin{tabular}{|c|c|c|c|c|c|c|c|c|}
\hline \multirow{2}{*}{\multicolumn{2}{|c|}{ Caractére }} & \multicolumn{7}{|c|}{ Profil } \\
\hline & & 1 & 2 & 3 & 4 & 5 & 6 & 7 \\
\hline \multicolumn{2}{|c|}{$\begin{array}{l}\text { Acide à partir de : } \\
\text { - Sorbitol } \\
\text { - Salicine } \\
\text { - Rhamnose } \\
\text { - Inositol } \\
\text { - Adonitol }\end{array}$} & $\begin{array}{l}- \\
+ \\
\overline{+}\end{array}$ & $\begin{array}{l}\overline{-} \\
+ \\
\text { ND } \\
\text { ND }\end{array}$ & $\begin{array}{l}+ \\
+ \\
+ \\
\text { ND } \\
\text { ND }\end{array}$ & $\begin{array}{l}+ \\
+ \\
+ \\
+ \\
\text { ND } \\
\text { ND }\end{array}$ & $\begin{array}{l} \pm \\
\pm \\
-\end{array}$ & $\begin{array}{l}+ \\
+ \\
\text { ND } \\
\text { ND }\end{array}$ & $\begin{array}{l} \pm \\
\pm \\
-\end{array}$ \\
\hline \multicolumn{2}{|c|}{$\begin{array}{l}\text { Hydrolyse de : } \\
\text { — Caséine } \\
\text { - Tributyrine }\end{array}$} & $\overline{-}$ & $\overline{-}$ & $\overline{-}$ & $\overline{-}$ & $\overline{-}$ & $\overline{-}$ & - \\
\hline \multicolumn{2}{|l|}{$\begin{array}{l}\text { Culture à : } \\
-7^{\circ} \mathrm{C} \\
-41^{\circ} \mathrm{C} \\
-45^{\circ} \mathrm{C}\end{array}$} & $\begin{array}{l}+ \\
+ \\
+\end{array}$ & $\begin{array}{l}+ \\
+ \\
+\end{array}$ & $\begin{array}{l}- \\
+ \\
-\end{array}$ & $\underline{+}$ & $\begin{array}{l}+ \\
+\end{array}$ & $\begin{array}{l}\overline{+} \\
+ \\
+\end{array}$ & $\begin{array}{l}\overline{+} \\
+\end{array}$ \\
\hline \multicolumn{2}{|c|}{ Formation d'indole : } & - & - & - & - & + & + & + \\
\hline $\begin{array}{l}\text { Nombre } \\
\text { de souches }\end{array}$ & $\begin{array}{l}\text { classées (a) } \\
\text { identifiées (b) }\end{array}$ & $\begin{array}{r}137 \\
8\end{array}$ & $\begin{array}{l}57 \\
13\end{array}$ & $\begin{array}{r}11 \\
2\end{array}$ & $\begin{array}{r}10 \\
2\end{array}$ & $\begin{array}{l}48 \\
16\end{array}$ & $\begin{array}{r}26 \\
6\end{array}$ & $\begin{array}{r}15 \\
4\end{array}$ \\
\hline \multicolumn{9}{|c|}{$\begin{array}{l}\text { ND : non déterminé. } \\
\text { (a) : sur un total de } 652 \text { souches testées. } \\
\text { (b) : méthode API } 20 \mathrm{E} \text { ou de GAviNI et al. (1982). }\end{array}$} \\
\hline
\end{tabular}




\section{TABLEAU 4 - TABLE 4}

Profils les plus fréquents des bactéries coliformes lactose moins à la surface des fromages

Most frequent types of lactose-negative coliform bacteria on the surface of cheese

\begin{tabular}{|c|c|c|c|c|c|}
\hline \multirow{2}{*}{ Caractère } & \multicolumn{5}{|c|}{ Profil } \\
\hline & 1 & 2 & 3 & 4 & 5 \\
\hline $\begin{array}{l}\text { Acide à partir de : } \\
\text { - Sorbitol } \\
\text { - Salicine } \\
\text { - Rhamnose } \\
\text { - Inositol } \\
\text { - Adonitol }\end{array}$ & $\begin{array}{l}- \\
\pm \\
-\end{array}$ & $\begin{array}{l}- \\
\pm \\
-\end{array}$ & $\begin{array}{l}- \\
+ \\
+ \\
-\end{array}$ & $\begin{array}{l}+ \\
+ \\
\mathrm{v} \\
\mathrm{v}\end{array}$ & $\begin{array}{l}+ \\
+ \\
v \\
v\end{array}$ \\
\hline $\begin{array}{l}\text { Hydrolyse de : } \\
\text { - Caséine } \\
\text { — Tributyrine }\end{array}$ & - & $\overline{-}$ & $\overline{-}$ & $\begin{array}{l}+ \\
+\end{array}$ & $\begin{array}{l}+ \\
+\end{array}$ \\
\hline $\begin{array}{r}\text { Culture à : } \\
-7^{\circ} \mathrm{C} \\
-41^{\circ} \mathrm{C} \\
-45^{\circ} \mathrm{C}\end{array}$ & $\frac{ \pm}{-}$ & $\begin{array}{l}+ \\
+ \\
-\end{array}$ & $\begin{array}{l}+ \\
+ \\
-\end{array}$ & \pm & $\begin{array}{l}+ \\
+ \\
-\end{array}$ \\
\hline Formation d'indole : & - & - & - & - & 一 \\
\hline \begin{tabular}{l|l}
$\begin{array}{l}\text { Nombre } \\
\text { de souches }\end{array}$ & $\begin{array}{l}\text { classées (a) } \\
\text { identifiées (b) }\end{array}$
\end{tabular} & $\begin{array}{l}9 \\
5\end{array}$ & $\begin{array}{r}46 \\
5\end{array}$ & $\begin{array}{r}43 \\
6\end{array}$ & $\begin{array}{r}17 \\
3\end{array}$ & $\begin{array}{r}19 \\
5\end{array}$ \\
\hline
\end{tabular}

$\mathrm{v}$ : caractère variable.

(a): sur un total de 343 souches testées.

(b) : méthode API 20E ou de Gavini et al. (1982).

200-250 $\mu \mathrm{m}$ ) au dixième-onzième jour (figure $8 \mathrm{~A}$ ) puis constante jusqu'à la fin de l'affinage. A ce stade, les cellules paraissaient en bon état physiologique (figure $8 \mathrm{~B}$ ).

Du Geotrichum, facilement reconnaissable à ses courts conidiophores, apparaissait très tôt également : il envahissait la surface du fromage vers 5-6 jours puis formait une couche de 200 à $400 \mu \mathrm{m}$ d'épaisseur superposée à celle des levures (figure 8A). Le Penicillium apparaissait vers le sixième jour (figure $8 \mathrm{C}$ ). A la troisième semaine, il formait un tapis de 450 à $600 \mu \mathrm{m}$ d'épaisseur mais présentait, dès la deuxième semaine, des signes de sénescence (irrégulier, formation de «cordes») qui s'accentuaient par la suite (figure 8D). 


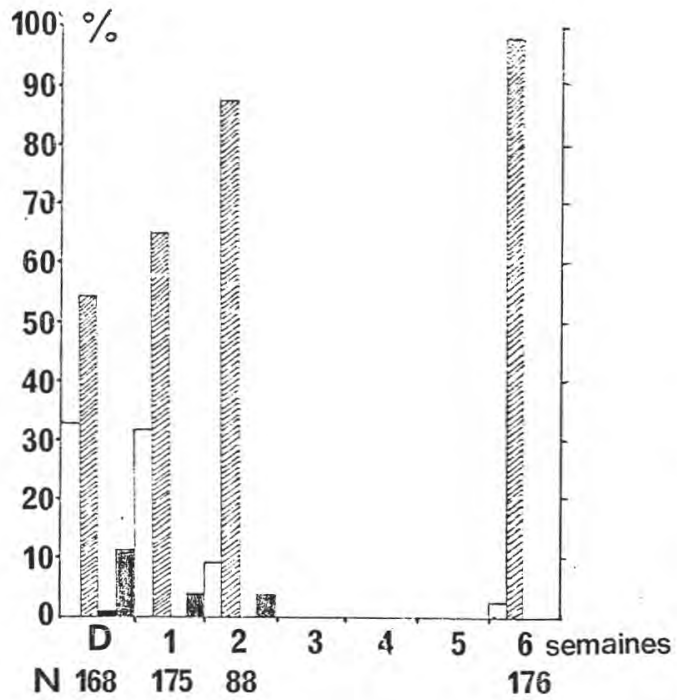

fig. 7

Fréquence des principales espèces de bactéries coliformes lactose plus trouvées à la surface des fromages (identification présomptive à partir des profils du tableau 3).

D : fromage au démoulage ; $\mathrm{N}$ : nombre de souches caractérisées. En blanc : $E$ coli, hachuré : $H$. alvei, noire : $S$. liquefaciens, gris: C.freundii.

Most frequent species of coliform bacteria found on the surface of cheese (Presumptive identification using the pofiles of Table 3).

$D$ : cheese at taking out from moulds ; $N$ : number of isolates. Key : white : E. coli, hatched : H. alvei, black : S. liquefaciens, grey : C. freundii.

Diverses formes de bactéries (streptocoques, cocci, bâtonnets) ont été observées à différents stades d'affinage des fromages. Le fait le plus marquant est peut-être la présence habituelle d'amas de cellules ayant la morphologie des bactéries corynéformes sur le tapis mycellien formé par le Penicillium et non pas au contact direct du fromage (figures 8D et $8 \mathrm{E})$.

\section{DISCUSSION}

La présente étude confirme les différences quantitatives et qualitatives entre usines, sur le plan de la flore bactérienne se développant à la surface des fromages. Par contre, les variations d'une saison à l'autre sont relativement plus faibles. Cela signifie que cette flore est plus dépendante de la technologie mise en œuvre dans chaque usine que de facteurs extérieurs.

C'est pour les bactéries halotolérantes que ces différences sont les plus importantes. Celles-ci ne peuvent être reliées directement à la qualité bactériologique du lait mis en œuvre, étant donné la position intermédiaire, pour tous les types microbiens, des usines I et IVR utilisant du lait réfrigéré en partie ou en totalité. Elles ne peuvent être non plus 

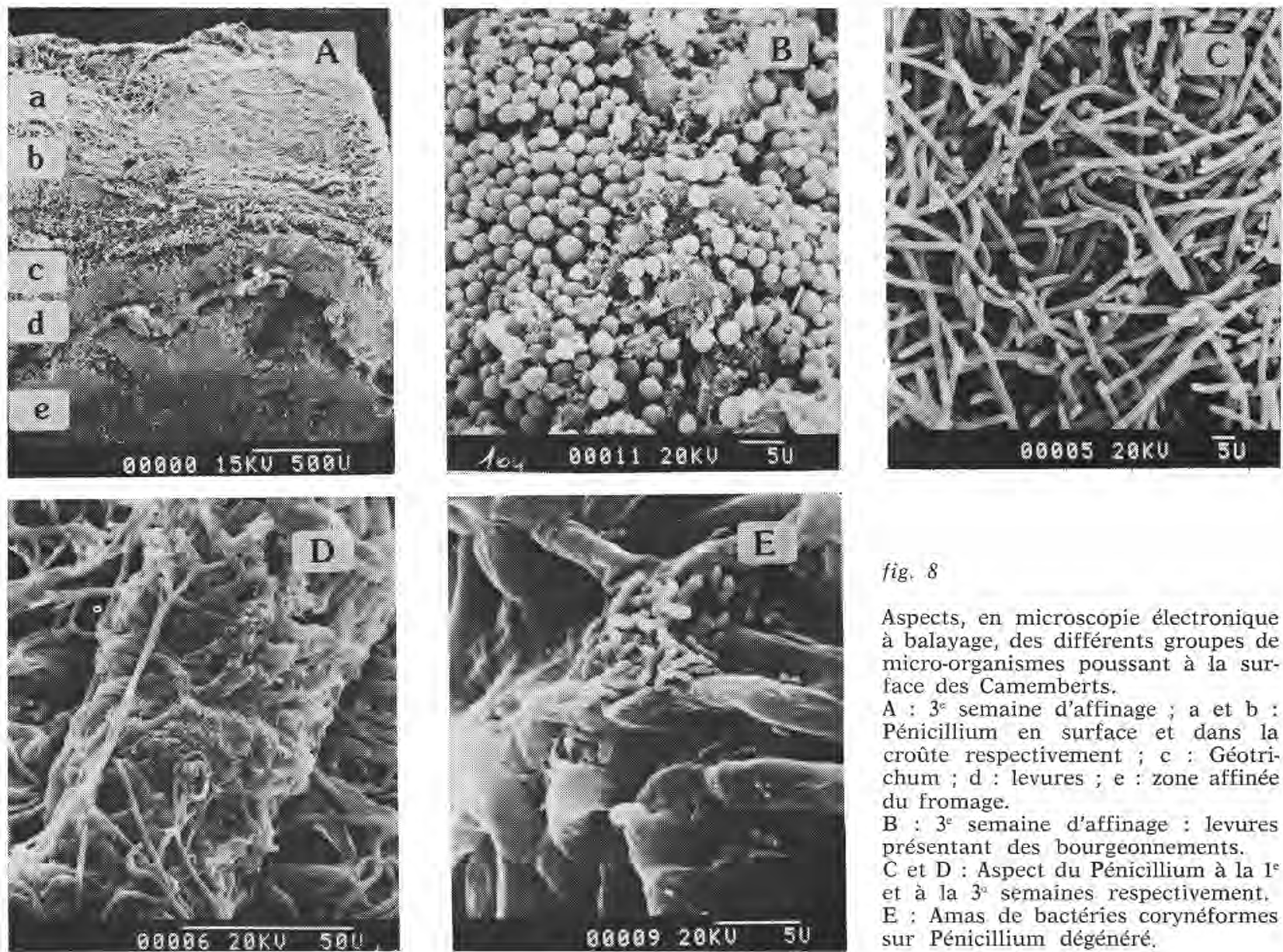

fig. 8

Aspects, en microscopie électronique à balayage, des différents groupes de micro-organismes poussant à la surface des Camemberts.

$\mathrm{A}: 3^{\mathrm{e}}$ semaine d'affinage; $\mathrm{a}$ et $\mathrm{b}$ : Pénicillium en surface et dans la croûte respectivement : $c$ : Géotrichum ; $d$ : levures ; e : zone affinée du fromage.

B : $3^{e}$ semaine d'affinage : levures présentant des bourgeonnements.

C et D : Aspect du Pénícillium à la 1 et à la $3^{\circ}$ semaines respectivement. E : Amas de bactéries corynéformes sur Pénicillium dégénéré.

Scanning electron microscopy of the surface of cheese at different periods of ripening.

$A: 3 r d$ week $; a$ and $b$ : Penicillium on the surface and in the rind respectivety $; c:$ Geotrichum; $d: y e a s t s ;$ $e$ : ripened zone of cheese.

$B$ : $3 r d$ week : yeasts showing buds.

$C$ and $D$ : Penicillium appearance at the 1 st and $3 r d$ weeks respectively, E: Microcolony of coryneform bacteria on degenerated Penicillium. 
attribuées uniquement au planchage des fromages à la fin du séjour au haloir (seule différence évidente entre les usines II et III) car l'usine IV, qui met aussi en œuvre cette technique, devrait alors avoir des résultats plus ressemblants à ceux de l'usine III. On doit donc admettre qu'il existe, entre usines, des variantes technologiques dont on n'a pas tenu compte et/ou des «microbismes» ambiants (flore du matériel ou de l'air) particuliers.

Quoi qu'il en soit, il importe de savoir si ces différences ont une incidence significative sur le goût des fromages. En particulerer, si le développement du «ferment du rouge » (bactéries corynéformes orange) s'accompagne de l'apparition ou du renforcement net du caractère alliacé des fromages, puisque, dans la flore bactérienne halotolérante, seules les bactéries corynéformes orange peuvent produire du méthanethiol.

Pour la flore lactique et pour les levures les courbes étaient relativement parallèles et semblables à celles obtenues par Lenoir (1963). On pourrait penser qu'il s'agit surtout des différences de niveaux, celles-ci pouvant être dues à la qualité bactériologique du lait mis en ouvre. En effet, ces micro-organismes se développant peu ou pas du tout dans le lait réfrigéré, ils sont, dans le lait de fabrication préparé avec du lait refroidi, à un niveau inférieur à celui du lait de fabrication préparé avec du lait non réfrigéré. Durant la fabrication du fromage, la température du lait puis du caillé $\left(30-35^{\circ} \mathrm{C}\right)$ permet une multiplication rapide de ces micro-organismes. L'acidification du caillé explique facilement leur diminution au cours de la première semaine. Dans l'étape suivante (haloir à $10-12^{\circ} \mathrm{C}$ pendant $10-15$ jours), ils progressent modérément puis pendant la conservation (28 à 32 jours entre 4 et $6^{\circ} \mathrm{C}$ ), du fait d'une température insuffisamment élevée, ils se maintiennent au niveau atteint au stade précédent. Cependant, un changement dans la nature de la flore dominante a pu se produire comme cela a été observé par Lenoir et Auberger (1966) pour les levures et par Kikuchi (1966) pour la flore lactique. L'apparent bon état physiologique des levures, révélé par la microscopie électronique à balayage, s'explique donc par leur multiplication. Les courbes ondulantes, pour les deux types de micro-organismes, peuvent alors être attribuées à la superposition de courbes en cloche (croissance plus déclin plus ou moins accentués.) des espèces ou types microbiens constituant chacune de ces flores. Cette hypothèse demanderait à être vérifiée pour la flore lactique, en raison du rôle possible de celle-ci dans l'affinage des fromages (Kikuchi et Takafuji, 1970).

Les bactéries coliformes (lactose + ou - ) arrivent, en fin d'aftinage, à un niveau élevé (plus de $10^{7} / \mathrm{g}$ ) à la surface de la plupart des fromages. Ceux fabriqués avec du lait réfrigéré en contiennent moins, ce qui semble indiquer que ces bactéries proviennent du lait. Cependant, une contamination des fromages par le matériel de l'usine pourrait également se produire. 
La diminution du niveau de cette population durant la première semaine est un phénomène déjà observé pour des Camemberts fabriqués avec du lait pasteurisé (Mourgues et al., 1977 ; Rutzinski et al., 1979). L'acidité de la pâte en est probablement la cause pincipale (Névot et al., 1962).

La remontée ultérieure du nombre de ces bactéries a été également constatée par ces auteurs. On doit se rappeler qu'elle ne se produit qu'à la surface des fromages (Richard et Zadi, 1983), ce qui signifie qu'elle est plus dépendante du $\mathrm{pH}$ et de la nature du substrat que de la température d'affinage.

Mourgues et al. (1977) ont également trouvé que la flore dominante des camemberts au lait pasteurisé était, en fin d'affinage, dominée par Hafnia alvei. Nos résultats corroborent ceux de ces auteurs et s'expliquent aisément : après une semaine, le $\mathrm{pH}$ des fromages remonte, ce qui favorise la reprise de la croissance des bactéries coliformes. Cependant, la température du haloir $\left(10-12^{\circ} \mathrm{C}\right)$ puis le stockage en chambre froide $\left(4-6^{\circ} \mathrm{C}\right)$ ne permettent le développement que des espèces psychrotrophes, d'où les proportions de plus en plus faibles de $E$. coli dans la flore coliforme et de plus en plus élevées de $H$. alvei.

Le déclin général de $H$. alvei lactose + entre la troisième et la quatrième semaine d'affinage peut être attribué soit à une interaction avec le variant lactose — de cette espèce (production de biocines), soit à une interaction avec la flore halotolérante. Un effet inhibiteur du méthanethiol que produiraient les bactéries corynéformes orange (Lewis, 1980) peut cependant être écarté, puisque les fromages sur lesquels on trouve peu de ces bactéries (ceux de l'usine IV, par exemple) présentaient le même phénomène.

D'un point de vue technologique, il est possible que $H$. alvei joue un rôle aussi important dans l'affinage des fromages que la flore corynéforme, étant donné le niveau élevé atteint par cette espèce. Cela peut concerner la production plus ou moins directe de composés aromatiques (agréables ou non) ou être du domaine de l'écologie (interactions microbiennes à l'avantage ou non d'espèces utiles ou indésirables).

D'un point de vue hygiénique, on peut rejeter l'origine exclusivement fécale de $H$. alvei, puisque la plupart des souches sont psychrotrophes (Gavini et al., 1980). On en trouve d'ailleurs beaucoup plus dans le matériel de traite que sur la peau des mamelles (Richard et Braquehaye, 1984).

Il en est bien sûr tout autrement de E. coli. Comme l'ont montré Mourgues et al. (1977), le niveau atteint par cette espèce dans ce type de fromage dépend de celui du lait de fabrication. Par ailleurs, Frank et al. (1977) puis Tolle et al. (1981) ont montré que E. coli avait tendance à disparaître au cours de l'affinage des Camemberts fabriqués avec du lait pasteurisé mais à une vitesse qui semble dépendre des conditions d'affinage de ces fromages. Il est probable que cette vitesse soit influencée aussi par la nature et le niveau des autres espèces microbiennes 
présentes, du fait de leur interaction. L'évolution particulière de $E$. coli dans les Camemberts fabriqués avec du lait cru serait donc intéressante à étudier, car ces fromages ont une flore plus diversifiée et un niveau plus élevé que les fromages fabriqués avec du lait thermisé ou pasteurisé (Richard et Zadi, 1983).

Enfin, la microscopie électronique à balayage s'est révélée un outil d'appoint pour suivre l'évolution de la flore microbienne à la surface des Camemberts en révélant en particulier l'état physiologique des levures et du Penicillium, ainsi que la structure de l'association microbienne. A cet égard, la croissance des bactéries corynéformes sur le Penicillium dégénéré et non pas au contact direct du caillé pourrait avoir pour conséquence de diminuer le rôle de ces bactéries dans l'affinage de ces fromages.

\section{Remerciements}

Nous remercions vivement Micheline Rousseau, qui a suivi l'évolution de la flore des fromages en microscopie électronique, Marc Bigret, Hann Möller Andersen et Jean-Louis Brelle, pour leur contribution à l'étude de l'évolution des bactéries coliformes.

Nous sommes également reconnaissants envers Jean-Jacques Devoyod pour la lecture critique du manuscrit et ses suggestions.

Nos remerciements vont enfin aux fabricants de Camemberts qui ont bien voulu participer à l'étude et nous ont offert toutes facilités pour sa réalisation.

\section{Bibliographie}

ANONYME (1974). - Lait et produits laitiers. Dénombrement des bactéries coliformes. Méthode de routine B (VRB). Fédération Internationale de Laiterie (F.I.L.), Doc. 73, Bruxelles.

ANonyme (1980). - Lait et produits laitiers. Dénombrement des levures et moisissures (comptage des colonies à $25^{\circ} \mathrm{C}$ ). Norme provisoire F.I.L. 94.

Bousfield (I.J.) (1972). - A taxonomic study of some coryneform bacteria. J. Gen. Microbiol, 71, 441-455.

Dumont (J.P.), Roger (S.) et Adda (J.) (1976). - L'arôme du Camembert : autres composés mineurs mis en évidence. Le Lait, 56, 595-599.

Frank (J.F.), MaRth (E.H.) and Olson (N.F.) (1977). - Survival of enteropathogenic and nonpathogenic Escherichia coli during the manufacture of Camembert cheese. J. Food Protection, 40, 835-842.

Gavini (F.), Marais (B.) Leroy (G.), Izard (D.) et Leclerco (H.) (1980). - Essai de différenciation des souches d'Enterobacteriacae en fonction de leur origine. Zbl. Balkt. Hyg., I. Abt. Orig. C., 1, 188-192.

Gavini (F.), Oger (C.), Lefebvre (B.), Izard (D.) and Leclerco (H.) (1982). Development of a computer identification system for coliform strains. $J$. Appl. Macteriol., 52, 329-332.

Hemme (D.) and Richard (J.) (1985). - L-methionin catabolism and production of methanethiol by bacteria isolated from Camembert made with raw milk. J. Appl. Bacteriol. (soumis pour publication).

JoNes (D.), Watkins (J.) and ERICKSON (S.K.) (1973), - Taxonomically significant colour changes in Brevibacterium linens probably associated with a carotenoid-like pigment. J. Gen. Microbiol., 77, 145-150. 
KIKUCHI (T.) (1966). - Observation on Camembert cheese ripening. 17e Congrès Intern. Lait., D, 313-319.

KIKUCHI (T.) and TAKAFUJI (S.) (1970). - The importance of lactic acid bacteria in the ripening of Camembert cheese. $18^{\mathrm{e}}$ Congrès Intern. Lait., Tokyo, $1 \mathrm{E}, 381$.

Lenoir (J.) (1963). - La flore microbienne de Camembert et son évolution au cours de la maturation. Le Lait, 43, 262-270.

LENoir (J.) et Auberger (B.) (1966). - Contribution à l'étude de la flore microbienne du fromage du type Camembert. $17^{\mathrm{e}}$ Congrès Intern. Le Lait, D 2, 595-602.

LEwis (B.A.) (1980). - A study of the antifungal agent(s) produced by four strains of Brevibacterium. Dissertation Abstracts International, B, 41, 16551656.

Mourgues (R.), Vassal (L.), Auclair (J.), Mocouot (G.), Vandeweghe (J.) et Deschamps (N.) (1977). - Origine et développement des bactéries coliformes dans les fromages à pâte molle. Le Lait, 57, 131-149.

Nevot (A.), Mocouot (G.), Lafont (P.) et Plommet (M.) (1962). - Recherches sur les conditions de survie des bactéries pathogènes dans les fromages à pâte molle. Ann. Inst. Pasteur, 103, 128-134.

PARK (W.A.) and Holding (A.J.) (1966). - Identification of some common gram negative bacteria. Laboratory Practice, 15, 1124.

RICHARD (J.) (1981 a). - Rapid picking up and purifying of aerobics microorganisms. Laboratory Practice, 30, 342-344.

RICHARD (J.) (1981 b). - Classification adansonienne et identification de Pseudomonas psychrotrophes isolés du lait cru conservé à basse température. Annales de Microbiologie, 132 A, 171-182.

RICHARD (J.) et ZADI (H.) (1983). - Inventaire de la flore bactérienne dominante des Camemberts fabriqués avec du lait cru. Le Lait, 63, 25-42.

Richard (J.) et BRAqueHaye (C.) (1984). - Les bactéries coliformes du lait. Microorganismes et aliments. Origine des flores spontanées. Société Française de Microbiologie, Paris. In Science des Aliments, numéro spécial.

Rousseau (M.) (1984). - Study of the surface flora of traditional Camembert cheese by scanning electron microscopy. Milchwissenschaft, 39, 130-135.

RUTZiNSKI (J.H.), MARTH (E.M.) and Olson (N.F.) (1979), - Behavior of Enterobacter aerogenes and Hafnia alvei species during the manufacture and ripening of Camemberts cheese. J. Food Protection, 42, 790-793.

SANSONETTI (F.) (1930). - Sur les flores bactériennes et fongiques des caillés de lait. Rôle des symbioses dans la maturation du Camembert. Le Lait, 10, 627-640, 782-793, 858-874, 1109-1122.

Tolle (A.), Оtтe (I.) und Suhren (G.) (1981), - Zur dynamik der produktspezifischen heimflora und von coliformen Keimen/E. coli während des erstellungsprozesses von Camembertkäse. Milchwissenschaft, 36, 5-9.

Z $\mathrm{ADI}$ (H.) (1981). - Thèse : Etude de la flore bactérienne non lactique des Camemberts fabriqués de façon traditionnelle. Université de Paris-Sud, Centre d'Orsay. 